\title{
Estado actual y transformaciones de la arquitectura de la vivienda tradicional likan antai. Los casos de Ayquina, Caspana y Toconce, Chile
}

\section{Transformations and current state of the likan antai traditional housing architecture. The cases of Ayquina, Caspana and Toconce, Chile}

Natalia Jorquera ${ }^{1}$ (D) https://orcid.org/0000-0002-6230-8110

Sophia Valle-Cornibert ${ }^{2}$ (D) https://orcid.org/0000-0002-3719-7519

Yanko Díaz ${ }^{3}$ (D) https://orcid.org/0000-0002-1211-8757

${ }^{1}$ Departamento de Arquitectura, Universidad de Chile, Santiago, CHILE.

Email: nataliajorquera@uchilefau.cl

${ }^{2}$ Centre for International Development, Northumbria University, Newcastle, UNITED KINGDOM.

Email: sophia.valle-cornibert@northumbria.ac.uk

${ }^{3}$ ONG POLOC, Santiago, CHILE. Email: yankodiaztoledo@gmail.com

\section{Resumen}

El presente artículo dará a conocer el estado actual, en términos arquitectónicos y constructivos, de la vivienda tradicional likan antai de diez poblados en torno al salar de Atacama y el río Loa, en la región de Antofagasta, Chile, para luego detenerse en las principales transformaciones de la arquitectura, tomando como casos de estudio específicos los poblados de Ayquina, Caspana y Toconce. Con ello se dará cuenta del tránsito que han experimentado la arquitectura y las prácticas constructivas ancestrales, desde el uso exclusivo de materiales naturales disponibles en el entorno inmediato -en especial la piedra- al empleo paulatino de elementos industrializados, lo que ha llevado a una diversificación de la arquitectura de la vivienda vernácula andina, subsistiendo, sin embargo, patrones arraigados a la forma de habitar likan antai.

Palabras clave: vivienda andino-atacameña, arquitectura vernácula, cultura constructiva, río Loa, habitar likan antai. 


\begin{abstract}
This article presents the current state, in architectural and construction terms, of the likanantai traditional housing of ten villages around the Salar de Atacama and the Loa River, in the region of Antofagasta, Chile. The main architecture transformations will be analyzed in depth, looking at the villages of Ayquina, Caspana and Toconce as specific cases of study.Here we will evidence the transitions from ancestral architecture and construction practices -based in the exclusive use of natural materials available in the immediate environment, especially the stone-, to the gradual use of industrialized constructive elements, which has led to the diversification of the architecture of the Andean vernacular dwelling, nevertheless, with still subsisting patterns rooted in the way of inhabiting likan antai.
\end{abstract}

Keywords: Andean-atacameño housing, vernacular architecture, building culture, Loa river, Inhabiting likan antai.

Recibido: 9 septiembre 2019. Aceptado: 29 septiembre 2020 


\section{Introducción}

A lo largo del siglo XX la arquitectura andina ha sido objeto de interés de numerosos arquitectos e historiadores, quienes han descrito aspectos tan variados como la forma física, los usos y las tipologías existentes (Benavides, Márquez de la Plata y Rodríguez, 1977; Benavides y Gutiérrez, 2006), las formas locales y comunitarias de construcción (Tomasi, 2009; Šolc, 2011; Tomasi y Rivet, 2011), los valores patrimoniales (Gross, 2006 y 2015; Jorquera, 2010, entre otros), y recientemente, los aspectos de sostenibilidad de la arquitectura tradicional (Chandía, 2013; Escobar, 2017). Pocos estudios, sin embargo, mencionan las transformaciones que ha sufrido dicha arquitectura en las décadas recientes, transformaciones que se caracterizan por el reemplazo de los materiales de construcción ancestrales como la piedra, el adobe y la paja brava por elementos industrializados como el bloque de cemento y la plancha de zinc, lo cual ha repercutido en el cambio de la morfología e imagen tradicional de la arquitectura, así como también en las formas de habitar y construir colectivo.

Para comprender el origen de las mencionadas transformaciones, se debe partir contextualizando las diversas problemáticas que han afectado a los poblados andinos de la precordillera y del altiplano chileno a partir de la llegada de la minería del salitre desde fines del siglo XIX, que desencadenó un proceso constante de "emigración de los habitantes del interior hacia las ciudades, de las regiones de Tarapacá y Antofagasta en busca de mejores perspectivas de desarrollo económico y de educación, provocando el abandono sostenido de los poblados" (Riquelme, 2006, p. 33), situación que se mantiene hasta el día de hoy, cuando gran parte de la población andina trabaja y reside en ciudades vinculadas a la minería. Esta situación, junto con la escasez hídrica y la falta de oportunidades laborales y servicios en los poblados ancestrales, ha fomentado el abandono y desencadenado un proceso de deterioro y mutación de la arquitectura tradicional. Sumado a ello, el arribo de materiales industriales como el cemento, la madera de pino y el vidrio, además de la carente protección del patrimonio arquitectónico, ha provocado la transformación y, en algunos casos, la desaparición completa de la arquitectura y de las formas de construir locales de los asentamientos rurales andinos como se conocían en el pasado.

La situación antes descrita se verifica también en los poblados likan antai, los cuales, a excepción de San Pedro de Atacama, han sido históricamente menos estudiados en la literatura, basada más bien en "lo aymara" para definir "la arquitectura andina". Esto puede deberse a que el pueblo likan antai es considerado "uno de los más pequeños en cuanto a su tamaño demográfico, estimándose en unos 12.000 el número de sus integrantes (aunque para algunos sólo llegan a 4.000)" (Rivera, 1997, p. 61) y también, como asevera el mismo autor, quizás el hecho de que las comunidades se encuentren concentradas en dos territorios distintos -la cuenca del río Salado en el Alto Loa y la cuenca de Atacama- donde en el primero los aspectos socioculturales se han hibridizado con las influencias de los lípez, aymaras y quechuas -y por tanto también su arquitectura-, y en el segundo, el corregimiento de Atacama la Grande, hoy San Pedro de Atacama, se ha llevado la atención de gran parte de los estudios. Esto último puede explicar por qué aparece menos en la literatura la arquitectura del resto de los poblados likan antai.

En ese contexto, el proyecto de investigación "Construir y habitar likan antai” busca analizar el estado actual de la arquitectura y las formas locales de construir la vivienda de los poblados en torno al salar de Atacama y el río Loa, conjugando herramientas arquitectónicas y antropológicas.

1 Proyecto ENLACE ENL14/18 financiado por la Vicerrectoría de Investigación y Desarrollo de la Universidad de Chile. 


\section{Metodología}

Para analizar el estado actual de la vivienda likan antai, se definieron los poblados en torno al salar de Atacama y el río Loa que constituirían los casos de estudio. Para ello se partió identificando todos los asentamientos humanos considerados likan antai según la información consignada en el registro de organizaciones y comunidades indígenas de la Corporación Nacional de Desarrollo Indígena (CONADI) y luego, a partir de revisión bibliográfica, entrevistas con fuentes oficiales ${ }^{2}$ y un primer trabajo de campo, se descartaron los ayllu en torno a San Pedro de Atacama por la dificultad de acceder a las viviendas por tratarse de asentamientos más bien rurales y con una trama de ocupación dispersa; San Pedro mismo por el grado de transformación de su arquitectura debido al impacto del turismo; de igual manera Talabre, pues la comunidad se negó a participar en la investigación, y los poblados no habitados o que constituyeran solo un sitio arqueológico, ya que se consideró esencial poder recoger el testimonio de los habitantes. Asimismo, con la finalidad de comparar las tipologías arquitectónicas y los modos de construir al interior de un mismo asentamiento, se optó por analizar solo los poblados donde existieran conjuntos de viviendas, es decir, poblados "urbanos", dejando de lado viviendas dispersas, por lo demás difícilmente localizables. Así, se definieron como casos de estudio los poblados de Toconao, Camar, Socaire, Peine y Tilomonte en la cuenca del salar de Atacama y Chiu Chiu, Ayquina, Cupo, Caspana y Toconce en el Alto Loa (Figura 1). Después de ello, se conjugaron diversos métodos de obtención de información a través de herramientas propias de la arquitectura y la antropología, como disciplinas principales de la investigación.

En primer lugar, se revisaron fuentes bibliográficas para caracterizar la vivienda andina y likan antai como subconjunto de la primera, y a partir de ello analizar su estado actual e identificar las transformaciones, utilizando también datos de la Cartografía Censal 2017 acerca de la materialidad y la presencia de "Vivienda tipo tradicional indígena". Luego se realizaron dos procesos de trabajo de campo, en los que, con un equipo formado por arquitectos y una antropóloga, se llevó a cabo un catastro de las viviendas tradicionales, definiendo primeramente un polígono central ${ }^{3}$ de análisis en cada uno de los diez poblados (Figura 2), correspondientes a los espacios de asentamiento fundacionales de cada comunidad, los que además responden a los centros con mayor concentración de viviendas.

En el primer trabajo de campo se registró por medio de fotografías, planos y fichas, la materialidad predominante, la morfología, el uso actual y el estado de conservación de las viviendas, y se realizaron 17 entrevistas en profundidad y semiestructuradas con los habitantes y dirigentes locales, recogiendo testimonios sobre las formas tradicionales y actuales de construir y habitar las viviendas.

En una segunda fase de trabajo de campo, se profundizó en los poblados de Ayquina, Caspana y Toconce como casos de estudio específicos, para analizar las transformaciones de la

2 Se entrevistó al director de Obras de la Municipalidad de San Pedro de Atacama y a la arquitecta Marcela Serrano, quien estuvo a cargo de la investigación "Levantamiento arquitectónico y cultura constructiva de la vivienda vernácula en San Pedro de Atacama" sobre los ayllu de San Pedro de Atacama, ambas entrevistas durante el mes de octubre del año 2018.

3 Para delimitar el área de análisis de cada poblado, se tomó como base el estudio "Asentamiento urbanos en territorios fronterizos, etapa de estudio zona Norte regiones I y II (Egumfedt-Jorgense, Uslar, Tiska y Samper, 1983)", en el cual se examinaron Ayquina, Caspana y Toconce en el año 1983 y se hizo un levantamiento del total de las construcciones existentes a esa fecha, que hoy corresponden a los polígonos centrales de los poblados. 


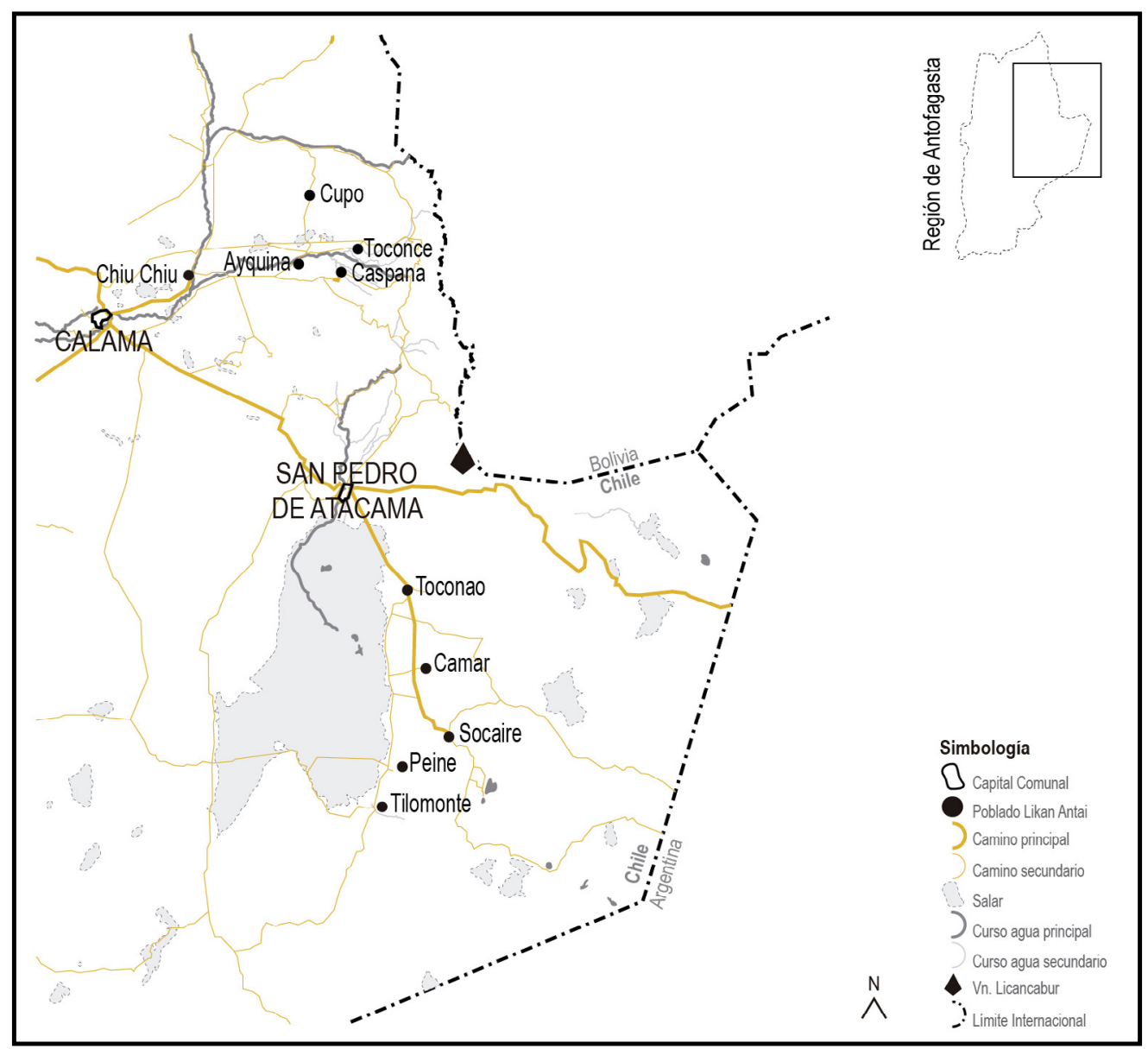

Figura 1. Mapa con los poblados likan antai casos de estudio.

Fuente: Autores.

arquitectura, utilizando la clasificación tipológica como principal herramienta de análisis. Esta consiste en la identificación de patrones físicos en común entre varias construcciones de un conjunto, que permiten su clasificación en "tipos”, basándose en la premisa que sostiene que la arquitectura puede "ser considerada como perteneciente a una clase de objetos reproducibles, caracterizados, como ocurre con los útiles o instrumentos, por una serie de atributos generales" (Moneo, 1978, p. 189). Esta herramienta es muy empleada en el análisis de la arquitectura vernácula, en el entendido de que esta "se concibe como actividad paralela a otros quehaceres y oficios artesanales... [donde como en una cesta o silla]... el objeto arquitectónico no solamente podía ser reproducido, sino que se suponía, se daba por sentado, que era reproducible" (Moneo, 1978, p. 189). Así, se realizó un análisis comparativo entre las viviendas de los mencionados polígonos centrales de los tres poblados, considerando parámetros de morfología, materialidad, forma y dimensión de los elementos principales (vanos de puertas y ventanas, techumbre), para obtener una clasificación en grupos con características comunes. Junto con ello, se realizaron 14 entrevistas semiestructuradas con habitantes de las tres comunidades, utilizando una metodología participativa que implicó invitar a las personas a identificar las partes y elementos constructivos a partir de dibujos isométricos de las viviendas. Además, se revisaron imágenes de viviendas existentes en los distintos poblados, para ver si los habitantes reconocían 
diferencias entre ellas y podían clasificarlas por grupos, preguntándoles si asociaban un nombre a esos grupos. De este análisis se obtuvo información sobre los principales patrones físicos en común en las construcciones, que siendo además atribuidos a las viviendas más "antiguas" (en palabras de los mismos habitantes) hizo que se pudiera reconocer una tipología de vivienda "tradicional", cuyas características coinciden, además, con la descripción que hace la literatura sobre la "vivienda andina" (ver siguiente sección). Esta vivienda "tradicional" fue entonces tomada como la base comparativa a partir de la cual observar las principales transformaciones arquitectónico-constructivas. Se quiso conjugar así una visión físico-estática de análisis de la vivienda likan antai, propia de la disciplina de arquitectura, gracias a la cual es posible definir un "original" y un "transformado", con la visión dinámica del uso y percepción de sus habitantes, desde la antropología, en la que, en cambio, esa diferencia no es tan marcada y se aprecia que las prácticas están en constante transformación.

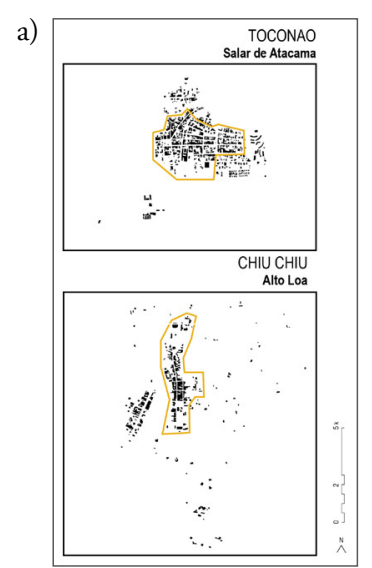

b)

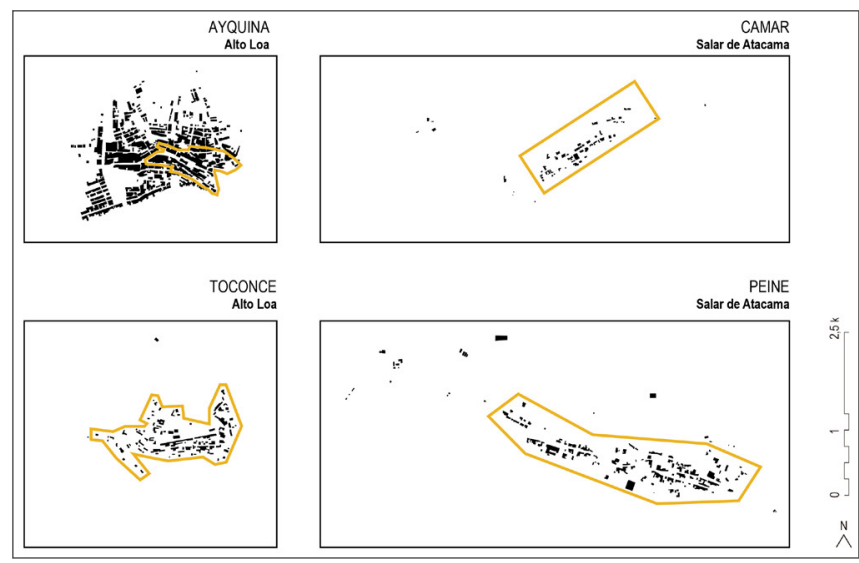

c)

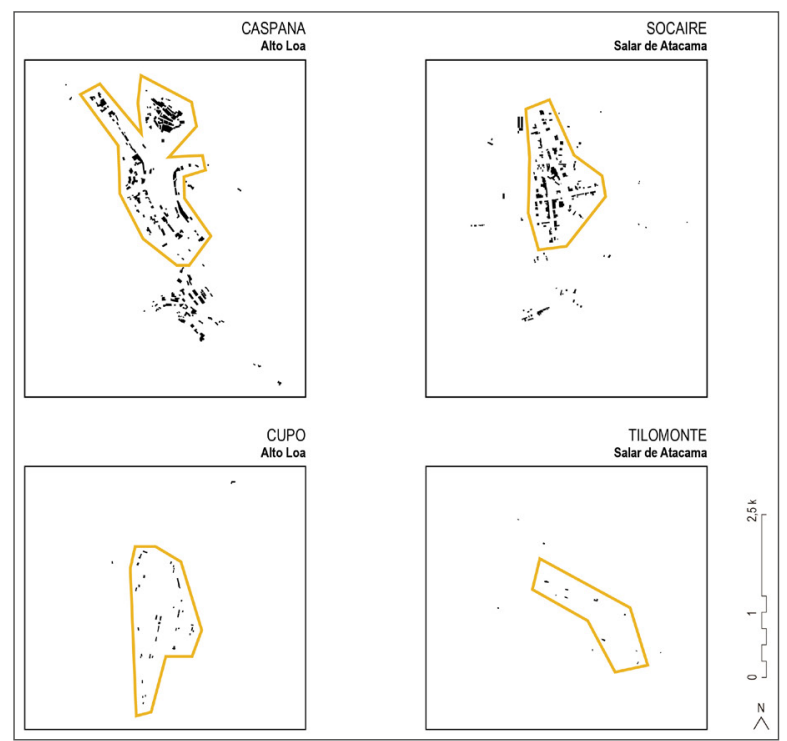

Figura 2. (a, b y c). Planos comparativos de los polígonos analizados en cada uno de los poblados. Fuente: Autores. 


\section{La vivienda tradicional likan antai y su estado actual}

Para analizar las transformaciones que presenta la vivienda likan antai en la actualidad, se precisa establecer los rasgos distintivos de la vivienda tradicional o vernácula. En una primera instancia, como se estableció en la Metodología, existió el desafío de consensuar un análisis teórico desde la arquitectura y la antropología, respecto a cómo se entiende lo tradicional. Por una parte, desde la arquitectura lo "tradicional" es sinónimo de "vernáculo", "popular", "doméstico", "nativo" y "autóctono", términos utilizados indistintamente, según se puede revisar en la literatura especializada de la mano de diversos autores (Rudofsky, 1964; Rapoport, 1969; Oliver, 1997; Tillería, 2010; Jorquera 2013 y 2014; Correia, Dipasquale y Mecca, 2014) que desde mediados de los ańos sesenta del siglo XX han documentado y puesto en valor la "arquitectura sin arquitectos" del mundo. Se entiende lo tradicional o vernáculo como aquella arquitectura construida por sus habitantes, usando los materiales disponibles en el territorio inmediato, a través de largos procesos de prueba y error que dan origen a prácticas y oficios arraigados al quehacer de la comunidad (Tillería, 2010; Jorquera, 2013). Uno de los rasgos distintivos de la arquitectura tradicional es su repetición, que da lugar a la creación de tipologías, como se estableció en el apartado Metodología. En efecto, la Carta del Patrimonio Vernáculo construido (1999) plantea que "lo tradicional se encuentra sólo en ocasiones representado por estructuras singulares. Es mejor conservado por el mantenimiento y preservación de los conjuntos y asentamientos de carácter representativo en cada una de las áreas" (Consejo Internacional de Monumentos y Sitios, 1999, p. 2). Por ello, lo que se aleja de esos patrones repetitivos, desde la arquitectura se considera como "no tradicional".

Desde la antropología, en cambio, se puede analizar esta categoría como diversa y no estática, siendo posible describir patrones de lo tradicional asociado a procesos de cambio o transformación sociocultural, en lugares y tiempos determinados. Desde este punto de vista, "se considera la tradición como una construcción social que se elabora desde el presente sobre el pasado" (Briones, 1994; Arévalo, 2004, p. 927; Madrazo, 2005). No obstante, cuando se confronta la idea de lo tradicional con las percepciones de los mismos entrevistados, existe un consenso al entender esta categoría como algo que alude al "pasado" o "antiguo". Debido a la diversidad de posturas en relación a la tradición, resulta un desafío consensuar un análisis de este concepto, además de que en el contexto de terreno estas mismas definiciones teóricas se matizan o rebaten. Sin embargo, consideramos valioso el resultado de la investigación transdisciplinar.

Para efectos de esta investigación, entonces, consideramos como vivienda tradicional aquella que posee características comunes y patrones tipológicos repetitivos en toda la macrozona andina, y que han sido ampliamente descritos por numerosos arquitectos, antropólogos e historiadores de la arquitectura (Montandón, 1950; Benavides 1988 [1941]; Šolc, 2011 [1975]); González, Gundermann e Hidalgo, 2014, entre otros): desde el punto de vista físico, se trata de un hermético paralelepípedo rectangular de forma ligeramente piramidal, con techumbre a dos aguas de pronunciada pendiente, una puerta de entrada en su centro y a veces uno o dos pequeños vanos destinados a ventana, todas características que develan el carácter de refugio de las viviendas ante el adverso clima del altiplano y la precordillera de los Andes. Las dimensiones son más bien reducidas en una proporción 2:1:1 (largo, ancho, alto), con medidas que en planta varían de $3 \mathrm{~m}$ de ancho por $6 \mathrm{~m}$ de largo en promedio; la altura en general alcanza los $3 \mathrm{~m}$ en la cumbrera (Šolc, 2011). Este módulo con un solo espacio interior, sin muros ni pilares que lo fragmenten, constituye la unidad básica habitacional de todo el mundo andino, y según establece Šolc analizando la vivienda aymara de Enquelga (2011 [1975]), la mayoría 
de las familias posee tres módulos, uno destinado a cocina, otro a dormitorio y uno como despensa; si una familia posee más bienes, tendrá más módulos, mientras por el contrario, si posee menos, le dará un uso combinado -usualmente de dormitorio y cocina a la vez-a un único módulo.

La vivienda tradicional es, en algunos casos, aún utilizada en su función de vivienda; como bodega de almacenaje -cuero, lana, carnes y recuerdos familiares-, o en otros casos como un espacio donde se realizan y mantienen las costumbres tradicionales. Don Andrés Anza explica que las viviendas tradicionales son utilizadas como un espacio conmemorativo "porque la gente sabe que sus abuelos, tatarabuelos, vivian ahi. Entonces ahi hacen las costumbres, por eso ellos mismos vienen, respetan lo que es lo más antiguo" (Andrés Anza, habitante de Caspana, com. pers., 2019).

En cuanto a los aspectos constructivos, como en toda arquitectura vernácula, la vivienda andina se materializa utilizando los recursos naturales del entorno inmediato como materiales de construcción, mimetizándose con el paisaje circundante (Tillería 2010; Jorquera 2013). Así, si en el territorio abundaba la tierra arcillosa, las casas eran construidas con adobe; si en las cercanías se hallaba una cantera, se extraían piedras y se realizaban con ellas gruesos muros de mampostería asentada en barro o en seco. Por su parte, han sido los cactus, chańares y algarrobos los elementos empleados para las estructuras de techumbre, en las que cualquier variación obedece a lo que el medio natural local ofrece.

En el caso específico de la vivienda likan antai, a partir de lo observado en terreno, las entrevistas a habitantes locales y la realización de ejercicios participativos, ${ }^{4}$ fue posible identificar los diferentes elementos constructivos y la denominación local que se otorga a cada uno (Figura 3). Así, respecto a los muros de la vivienda, a excepción de San Pedro de Atacama y los ayllu circundantes donde predomina el uso del adobe y el tapial (tierra apisonada al interior de un encofrado) y Chiu Chiu, donde se registran muros mixtos de piedra y adobe, los poblados del salar y del río Loa están construidos con gruesos muros de mampostería de piedra (Figura 4), con variaciones locales en relación a las diferencias ambientales existentes. Estas van desde la piedra volcánica extraída de cantera llamada liparita, la piedra laja, a piedras más pequeñas y redondas recolectadas, tipo piedra alemosca en Camar, piedra volcánica o poma en Socaire, o piedra tirá o cupeña en Cupo. Estos muros, gracias a la habilidad de sus habitantes-constructores, han logrado conservarse en el tiempo y además regular la temperatura interior de las viviendas, el aspecto que más valoran sus habitantes: "La ventaja de las construcciones antiguas, [es que] en el invierno [son] abrigaitas y en verano, fresquitas. Conservan la temperatura interior" (Manuel Tejerina, habitante de Camar, com. pers., 2018).

4 Como se explicó en la Metodología, este ejercicio participativo consistió en mostrar a los entrevistados un dibujo isométrico de la vivienda (Figura 3), para identificar y denominar las partes y elementos constructivos. 


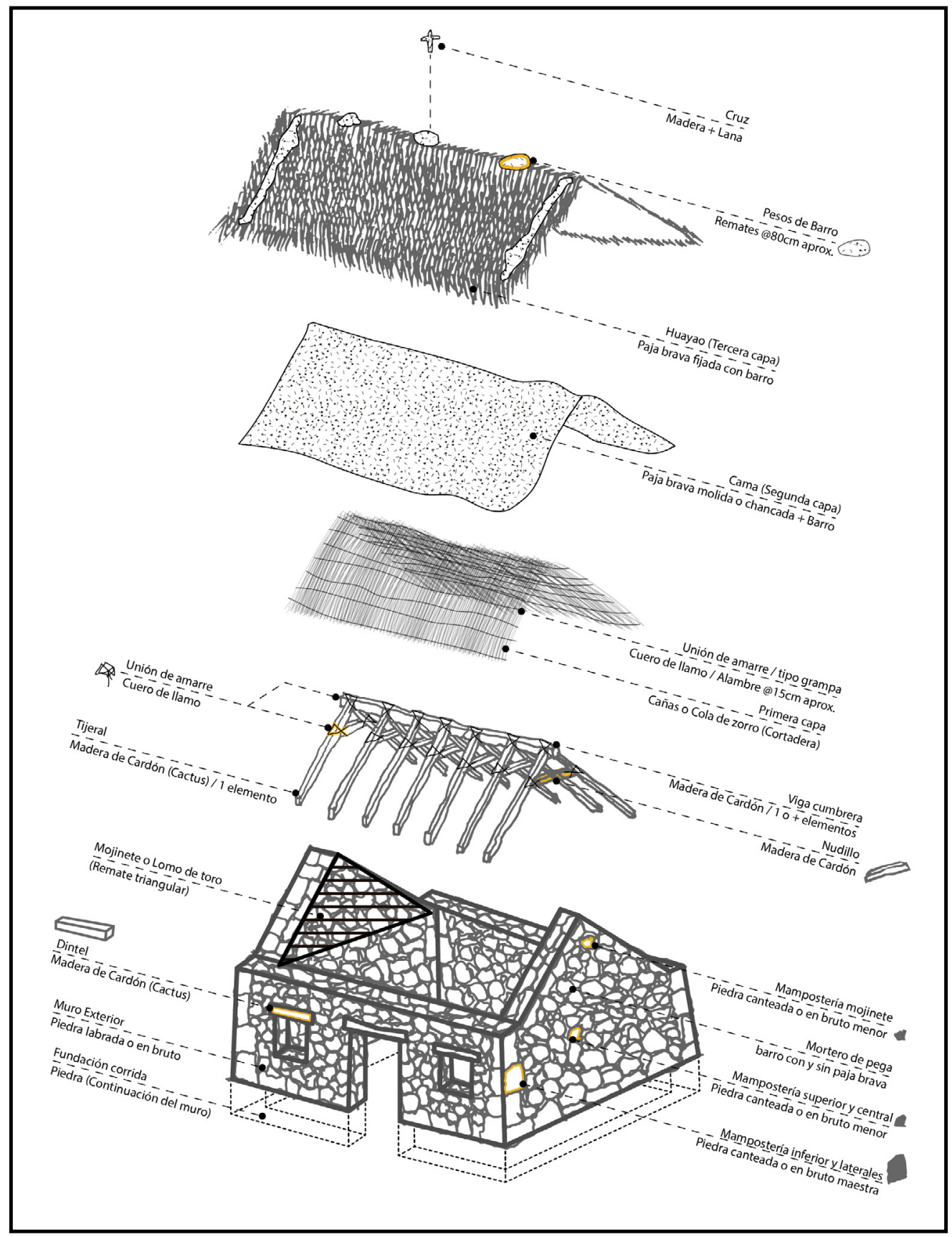

Figura 3. Dibujo isométrico con los principales elementos constructivos (denominaciones de los entrevistados) de la vivienda tradicional likan antai. Fuente: Autores. 


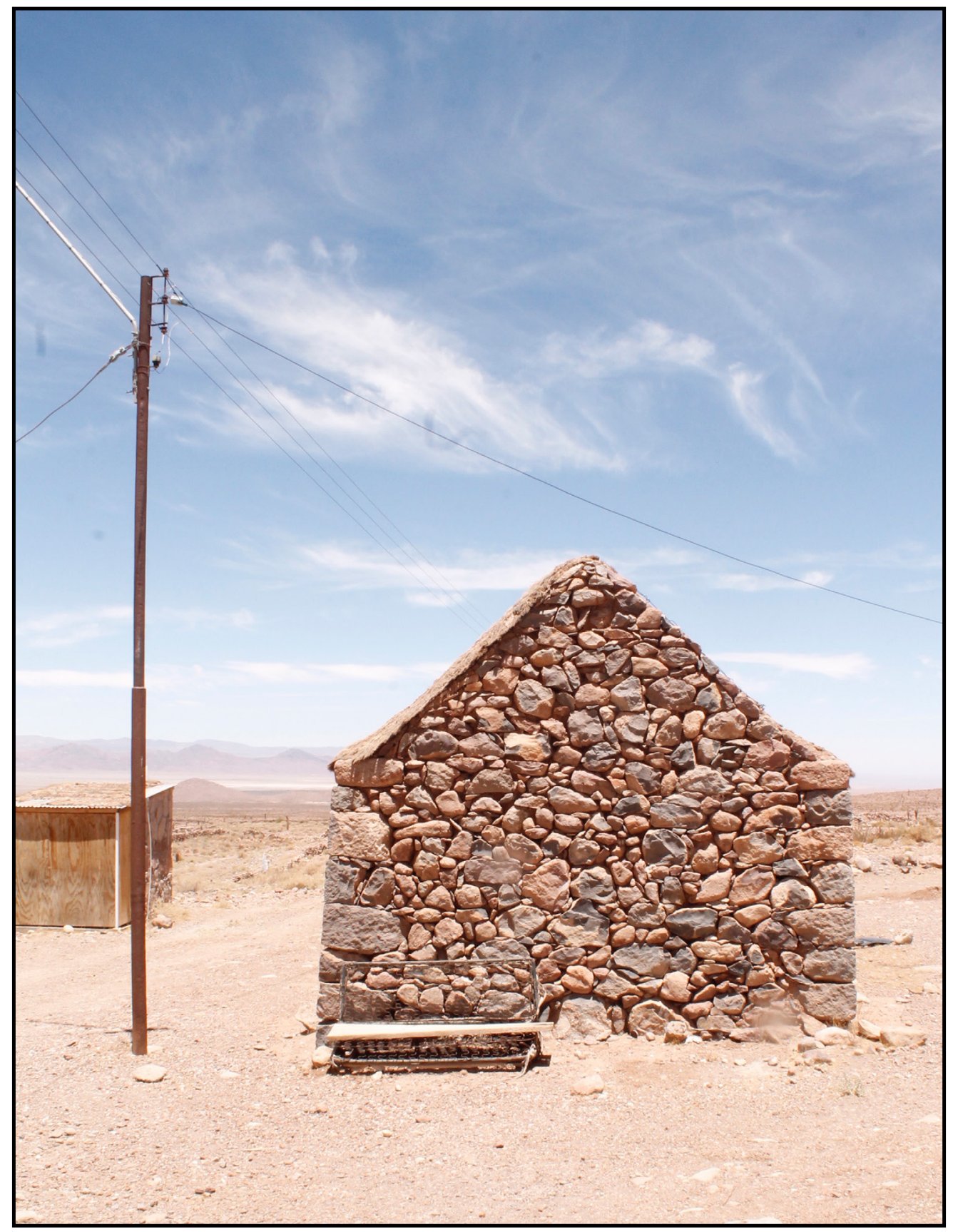

Figura 4. Vivienda tradicional likan antai de Cupo, construida con mampostería de piedra. Fuente: Autores. 
En cuanto a la techumbre, esta se construye empleando tijerales de par y nudillo con madera de algarrobo, chañar o cactus cardón, labrada a mano y articulada con amarres de cuero de llamo o alambre, sobre la cual se dispone una armadura de fibra vegetal de cańas o cola de zorro [cortaderas] que también es entretejida con cuero de llamo o alambre. Sobre ella se aplica una "cama de paja molida o chancada", que es el resultado de golpear la paja brava hasta obtener un molido fino. Finalmente una capa de paja brava remojada con barro, conocida en algunos pueblos como "huayao", que se aplica como terminación a la estructura del techo. En algunos casos, con el pasar de los ańos, se estuca exteriormente con una capa denominada "torteado", compuesta por barro y paja, para la reparación y mantención del techo frente a las precipitaciones. El pavimento, en cambio, se presenta como un continuo apisonado del suelo natural.

Todas las técnicas son artesanales y colectivas (Benavides, Márquez de la Plata y Rodríguez, 1977), se transmiten de padres a hijos (Kapstein, 2015 [1988]) y a lo largo del tiempo han generado saberes locales (Fullerton y Medina, 2017). Así, quienes construían con piedra, o los "maestros canteros" como son reconocidos, tenían conocimiento para determinar cuál era la piedra indicada a utilizar, cómo extraerla y cómo darle la forma apropiada para su colocación, además de un saber acerca de cómo debían ser unidas, considerando la firmeza o resistencia que se esperaba para el hogar. Como explica uno de los habitantes-constructores de Toconao:

Todo tiene su técnica, igual que la piedra, para quebrarla, usted no puede pegarle por el lado que se le ocurra, porque la piedra tiene una hebra. Tiene una técnica, por ejemplo, usted va en un principio cuando es grande, usted puede pegarle contra la hebra, pero cuando ya va quedando más o menos para después hacer la terminación de bloque, y ahi tiene que pagarle por la hebra, parejito, derechito (Emiliano Flores, Toconao, com. pers., 2018).

El buen uso de los materiales o recursos de la zona es lo que más destacan las generaciones que hoy habitan los pueblos, donde aún permanecen entre ellos algunos cultores del oficio, como don Emiliano, conocedores de estas técnicas aprendidas y replicadas de generación en generación.

Estimar el número actual de viviendas tradicionales que subsisten en los poblados likan antai no es fácil, pues gran parte de ellas han sido modificadas y se encuentran en un estado intermedio entre lo vernáculo y lo construido con materiales industrializados. Para efectos de esta investigación, se contabilizó como tradicional aquella vivienda con una morfología basada en un único paralelepípedo rematado por una cubierta a dos aguas, según lo descrito en la literatura, y que, en buen o mal estado, conserva las materialidades de piedra, barro, madera y paja antes descritas (Figura 5). Así, en los diez poblados analizados, la permanencia de viviendas tradicionales (Tabla 1) depende, en primera instancia, del emplazamiento de los asentamientos y las dinámicas socioeconómicas que han permeado el territorio en torno al salar de Atacama y la cuenca del río Loa. En el primer caso, el influjo del turismo internacional con epicentro en San Pedro y la cercanía a las mineras (Andes Travertine, Tuina, SQM Salar, SCL Chemetall y CMP El Laco) (SONAMI, Mapa Minero de Chile) han provocado impactos ecológicos, sociales y económicos en el territorio, repercutiendo en las prácticas constructivas ancestrales, lo cual ha tenido como efecto una transformación de los asentamientos y una disminución de las viviendas tradicionales; esto ocurre en Toconao, Camar, Socaire, Peine y Tilomonte, según se pudo apreciar en el trabajo de campo. En el caso de la cuenca del Loa, se presenta una situación un poco más dispar, en directa relación con la ubicación y el aislamiento geográfico; así, Chiu Chiu, debido a su cercanía de Calama $(30 \mathrm{~km})$ y la falta de protección y fiscalización por parte 
del Consejo de Monumentos Nacionales (CMN) a pesar de ser Zona Típica, es el poblado que presenta mayor transformación, restando pocos ejemplares de arquitectura tradicional. En el extremo opuesto se encuentra Cupo, pequeño asentamiento donde casi la totalidad de su arquitectura es de tipo tradicional; entremedio se encuentran los casos de Ayquina, Caspana y Toconce, cuyas transformaciones han sido paulatinas y aún es posible reconocer patrones ligados a la vivienda tradicional.

En cuanto al estado de conservación de las viviendas tradicionales presentes en cada poblado, se definieron tres criterios para determinarlo: malo, regular o bueno, excluyendo aquellas

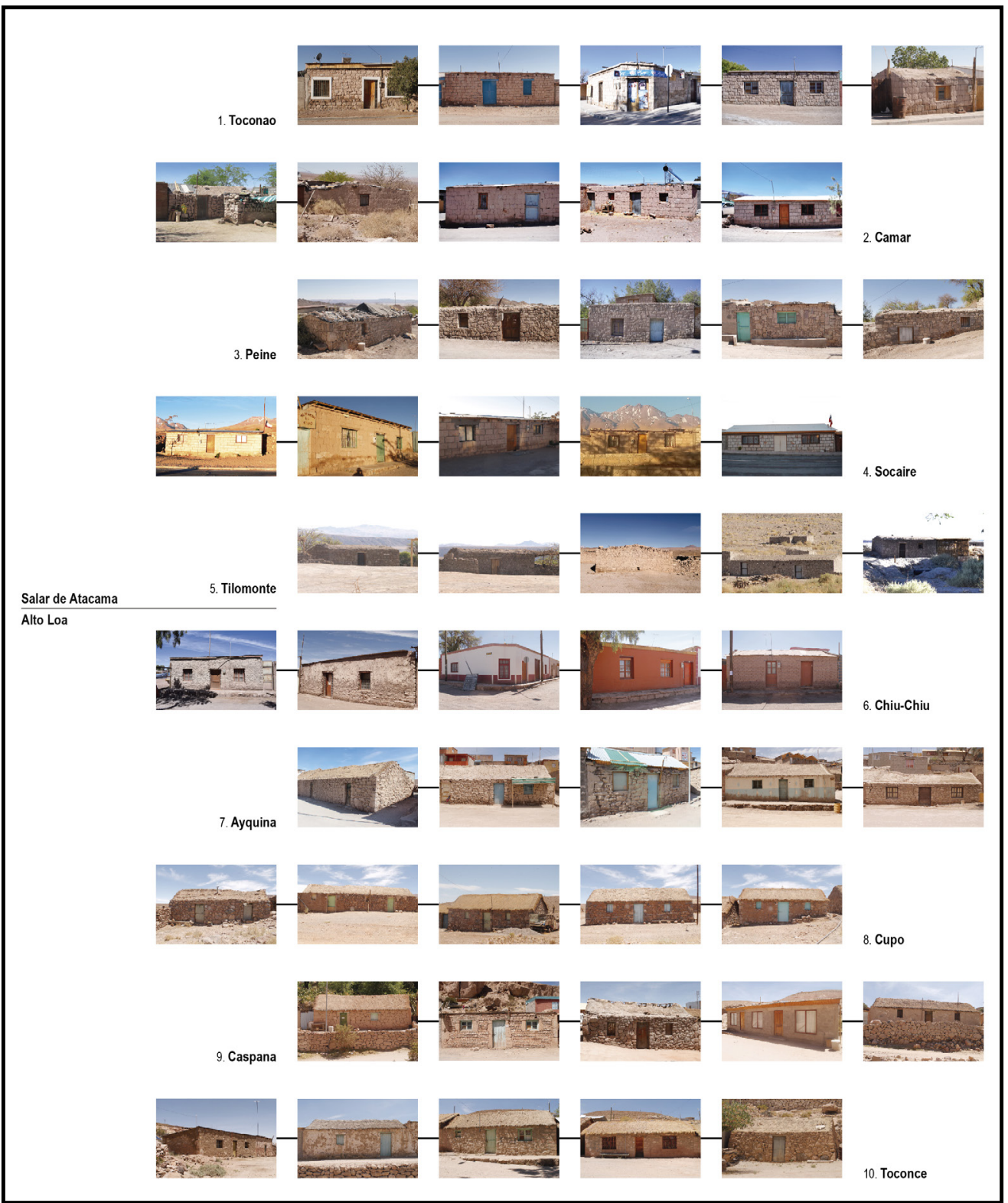

Figura 5. Ejemplos de viviendas tradicionales que subsisten en los diez poblados likan antai analizados. Fuente: Autores. 
viviendas en condición de ruina. La clasificación de "bueno" se consideró para viviendas que contaban con todas sus partes materiales íntegras (muros y techumbre); "regular" cuando faltaba alguna de sus partes o cuando estas habían sido reemplazadas por otros materiales (p.e., la situación de las techumbres de paja reemplazadas por planchas de zinc), y "malo" cuando presentaran modificaciones o dańos irreversibles. Las viviendas tradicionales en mejor estado de conservación se encontraron en los poblados de Toconao, Camar, Socaire y Cupo. En la Tabla 1 se identifica el estado de conservación general para cada poblado, considerando el criterio con mayor presencia entre todas las viviendas tradicionales levantadas en terreno.

Cabe mencionar que la disminución del número de viviendas tradicionales está relacionada -además de los fenómenos socioeconómicos mencionados- con el abandono de las técnicas de construcción tradicionales por situaciones que obedecen a fenómenos también externos. Así, por ejemplo, en el caso del uso de piedra, esta se extraía de las canteras mediante el empleo de explosivos artesanales - "pólvora negra"-, los cuales dejaron de utilizarse después de su prohibición en 1978 con la promulgación de la Ley 17.798 sobre control de armas y explosivos. Algo similar sucede con el cactus cardón empleado para vigas y otras carpinterías, cuya tala ha sido prohibida por la CONAF desde el año 2009. Otro factor que perjudica la conservación de las técnicas tradicionales es la edad de los habitantes, como advierte una de las abuelas del pueblo de Camar, quien relata haber construido su vivienda de piedra junto a su esposo fallecido, pero debido a que ella ya no cuenta con la fuerza física para realizar la mantención necesaria, se mudó a una vivienda hecha con bloques de cemento construida por sus hijos, abandonando la vivienda tradicional, que con el paso del tiempo se convirtió en escombros.

Tabla 1. Número de viviendas tradicionales en cada poblado y su estado de conservación.

\begin{tabular}{|l|c|c|c|c|}
\hline Poblado & Total de viviendas & $\begin{array}{c}\text { Viviendas } \\
\text { tradicionales }\end{array}$ & $\begin{array}{c}\text { Estado de } \\
\text { conservación } \\
\text { predominante }\end{array}$ \\
\hline Toconao & 308 & 11 & 3,6 & Malo \\
\hline Camar & 32 & 1 & 3,1 & Regular \\
\hline Peine & 156 & 10 & 0,4 & Regular \\
\hline Socaire & 74 & 0 & 100,0 & Bueno \\
\hline Tilomonte & 9 & 9 & 1,5 & Regular \\
\hline Chiu Chiu & 255 & 2 & 18,0 & Regular \\
\hline Ayquina & 47 & 46 & 48,9 & Bueno \\
\hline Cupo & 169 & 23 & 9,5 & Regular \\
\hline Toconce & 153 & 38 & 24,8 & Regular \\
\hline Caspana & 1333 & & & \\
\hline
\end{tabular}

Fuente: Elaboración propia. 
Llama la atención que el número de viviendas registradas como tradicionales en la presente investigación es muy superior al que aparece en la Cartografía Censal 2017 como "Vivienda tipo tradicional indígena" (Tabla 2), a pesar de que el censo registró la totalidad de las viviendas por cada poblado, lo que aparece como contradictorio; esto puede significar que muchas viviendas tradicionales no fueron censadas o bien que no fueron consideradas tradicionales por sus moradores, que son quienes dan la información. Respecto a la materialidad predominante, también es curioso que las viviendas con techumbre de "totora, paja", etcétera, y con muros de "adobe, barro, quincha, pirca u otro", según la denominación censal -es decir, materiales característicos de la vivienda vernácula-, tampoco coincide con el número de viviendas tradicionales registradas en el mismo censo. Un último dato interesante, que deja de manifiesto cómo los instrumentos de registro emanados desde el Estado no siempre son adecuados para levantar información sobre las realidades locales, es aquel sobre la materialidad predominante, que aglutina en una misma categoría, sin distinción alguna, las paredes de "bloque de cemento y ladrillo" con las de "piedra", tratándose las primeras de materiales industrializados disponibles en el comercio, mientras la piedra es un material local no estándar característico de la arquitectura tradicional likan antai. Por esta razón, ese dato impide discernir entre viviendas tradicionales y modernas, de allí que su número sea muy alto. En el levantamiento de la presente investigación, se consideró vivienda likan antai toda aquella que forma parte de la tipología tradicional descrita y sus derivadas.

Tabla 2. Resultados cartografía censal 2017.

\begin{tabular}{|c|c|c|c|c|c|c|}
\hline \multirow[b]{2}{*}{ Poblado } & \multicolumn{3}{|c|}{ Materialidad } & \multirow[b]{2}{*}{$\begin{array}{c}\text { Total con } \\
\text { presencia de } \\
\text { moradores }\end{array}$} & \multirow[b]{2}{*}{$\begin{array}{c}\text { Total } \\
\text { viviendas }\end{array}$} & \multirow[b]{2}{*}{$\begin{array}{l}\text { Viviendas } \\
\text { tipo } \\
\text { tradicional } \\
\text { indígena } \\
\text { (ruka, pae } \\
\text { pae, otra) }\end{array}$} \\
\hline & $\begin{array}{l}\text { Paredes de } \\
\text { albañilería: } \\
\text { Bloque de } \\
\text { cemento, } \\
\text { piedra o } \\
\text { ladrillo }\end{array}$ & $\begin{array}{c}\text { Paredes } \\
\text { de adobe, } \\
\text { barro, } \\
\text { quincha, } \\
\text { pirca u otro }\end{array}$ & $\begin{array}{c}\text { Techo de } \\
\text { totora, paja, } \\
\text { etc. }\end{array}$ & & & \\
\hline Toconao & 203 & 17 & 19 & 235 & 407 & 7 \\
\hline Camar & 23 & 0 & 1 & 25 & 39 & 1 \\
\hline Peine & 66 & 7 & 12 & 88 & 112 & 0 \\
\hline Socaire & 53 & 2 & 3 & 61 & 92 & 4 \\
\hline Tilomonte & $s / i$ & $s / i$ & $s / i$ & $s / i$ & $s / \mathrm{i}$ & $s / i$ \\
\hline Chiu Chiu & 62 & 29 & 5 & 145 & 288 & 0 \\
\hline Ayquina & 13 & 4 & 0 & 18 & 1540 & 2 \\
\hline Cupo & 5 & 2 & 3 & 9 & 92 & 18 \\
\hline Toconce & 17 & 2 & 4 & 23 & 217 & 25 \\
\hline \multirow[t]{2}{*}{ Caspana } & 44 & 7 & 13 & 54 & 340 & 37 \\
\hline & & & & & 3127 & \\
\hline
\end{tabular}

Fuente: Datos extraídos del Censo 2017. 


\section{Tipologías arquitectónicas y transformaciones de Ayquina, Caspana y Toconce}

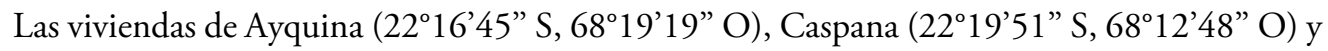
Toconce ( $\left.22^{\circ} 15^{\prime \prime} 51^{\prime} \mathrm{S}, 68^{\circ} 9^{\prime} 56^{\prime \prime} \mathrm{O}\right)$, poblados ubicados en el curso superior del río Loa sobre los $2900 \mathrm{msnm}$, como se mencionó, se encuentran en un estado de hibridación arquitectónica, en el que aún es posible reconocer patrones andinos likan antai-como las dimensiones generales de las viviendas, su volumetría y la imagen de la piedra canteada- mezclados con elementos constructivos contemporáneos -como la introducción de planchas de zinc, estucos de cemento, puertas y ventanas de aluminio y/o pino-, presentándose así como un escenario privilegiado para la observación de las dinámicas de transformación.

Mientras la introducción de nuevos elementos y materiales es algo que se ha verificado en los diez poblados en estudio, la permanencia de patrones andinos en estos tres poblados puede explicarse por varios factores:

- El aislamiento geográfico, que "puede ser visto en algún sentido como una ventaja, sólo en la medida que posibilita una lectura más genuina de un proceso evolutivo menos impactado por los efectos de la globalización" (Hurtado, 2012, p. 37).

- La lejanía respecto a los centros urbanos y al polo turístico internacional de San Pedro de Atacama y los circuitos aledaños.

- El reconocimiento y protección patrimonial estatal: Ayquina fue declarado Monumento Nacional en la categoría de Zona Típica en 1974 (CMN) y junto con Toconce se encuentran incluidos en la "Lista Tentativa", nómina preliminar elaborada por el Estado chileno de bienes que se considera que poseen un valor universal y que por lo tanto podrían ser postulados a la UNESCO como Sitio del Patrimonio Mundial (CMN, s.a.).

Así, para lograr obtener una caracterización y cuantificación de las transformaciones acaecidas en la vivienda tradicional de los tres poblados, se partió realizando un catastro de todas las viviendas presentes en los polígonos centrales de estudio, y a partir de la elaboración de una tabla donde se compararon los principales elementos morfológicos y constructivos (Tabla 3), se detectó la existencia de cuatro tipologías arquitectónicas, a las cuales se denominó "Tradicional", "Tradicional modificada", "Tradicional simulada" y "Disonante", siempre en relación con su cercanía o lejanía de los patrones tipológicos que permitieran identificar lo tradicional. Estas tipologías fueron analizadas de manera conjunta en los tres poblados, debido a la similitud, por su origen en común, de las construcciones encontradas.

Posteriormente, se realizó un ejercicio participativo con los entrevistados, que consistió en mostrar cuatro imágenes de viviendas correspondientes a cada tipología -sin antes mencionar la denominación otorgada-, para reflexionar sobre las principales características de cada una, y luego definirla o clasificarla según la impresión de los mismos habitantes y constructores locales. Si bien las cuatro imágenes corresponden a cada tipología previamente identificada, el alcance de este ejercicio fue que, además de profundizar en los aspectos arquitectónicos y materiales de la vivienda, se logró realizar un análisis con los entrevistados respecto a los procesos de transformación de la vivienda dentro de los tres poblados, dilucidando un esquema general de lo que sería el proceso de transformación de la arquitectura likan antai. 


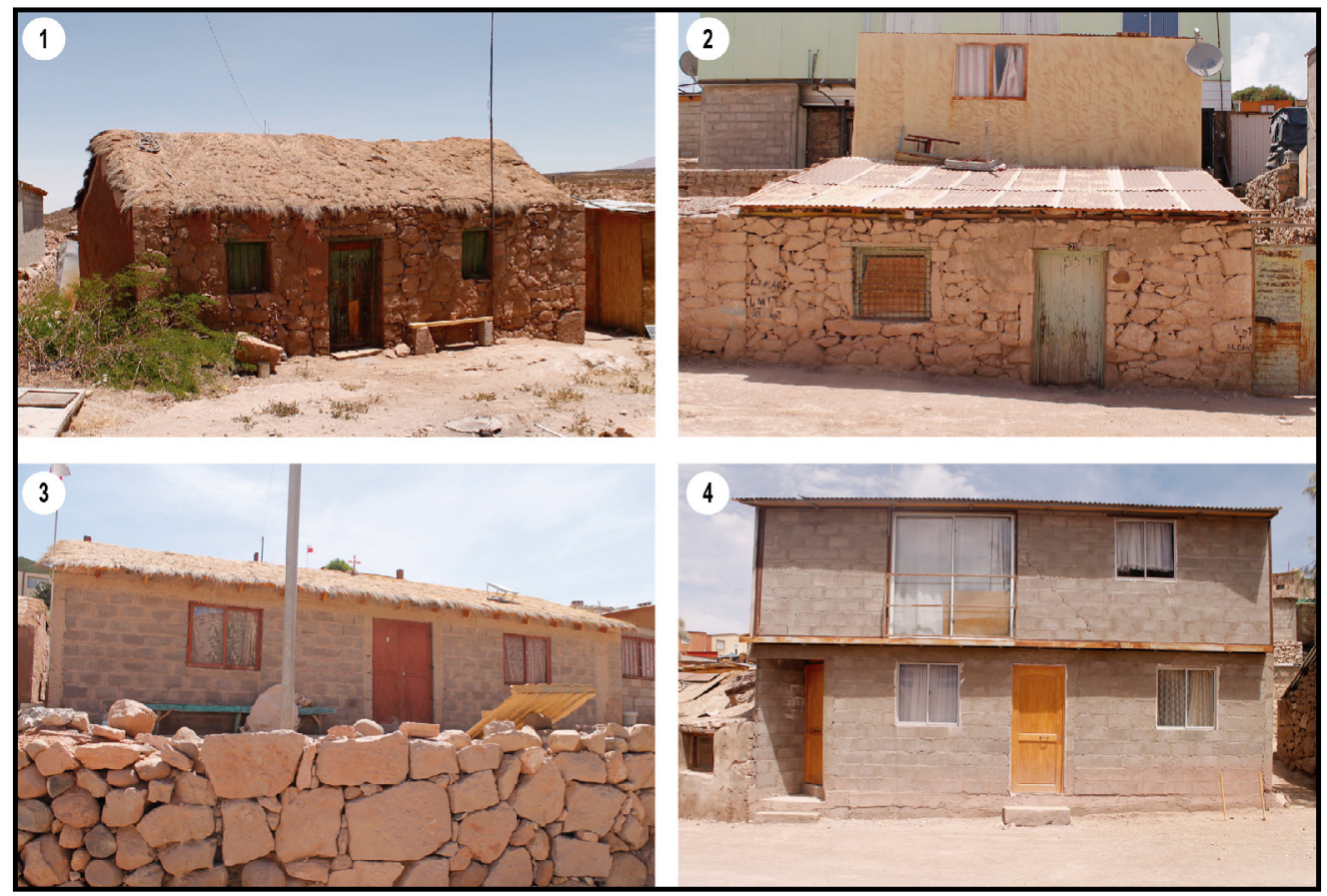

Figura 6. Cuatro imágenes utilizadas en ejercicio participativo, definidas como tipologías: 1. Vivienda tradicional; 2. Vivienda tradicional modificada; 3.Vivienda tradicional simulada, y 4. Vivienda disonante. Fuente: Autores.

A partir de las imágenes revisadas durante este proceso (Figura 6), surgió un conjunto de denominaciones locales - cabe mencionar que ninguno de los entrevistados repitió el nombre para cada imagen de la vivienda-, sin embargo, las características descritas de cada tipología fueron bastante homogéneas.

1. Vivienda "tradicional". Llamada por los habitantes "Casa típica", "Natural", "Casa autóctona", "Antigua", "Casa original de los pueblos".

Esta tipología corresponde a lo que se definió como vivienda tradicional anteriormente, es decir, una construcción que presenta como característica principal una volumetría de forma paralelepípeda, sobre la cual descansa una techumbre a dos aguas de madera, tierra y paja locales. Fue construida por los mismos habitantes de la zona, utilizando los materiales disponibles del entorno, dando lugar a muros de piedra asentados en seco o con mortero de barro. Además del umbral de acceso, algunas viviendas con el tiempo han incorporado pequeńos vanos destinados a ventana.

Se distinguen como las primeras construcciones o las más antiguas, y que en general tienen una conservación de muchos años.

Esa es una casa antigua, es el modelo de una casa antigua, con todo material de acá nomás, no hay material, mínimo habrá material de afuera, lo otro es todo piedra, techo, todo, casa natural,_la mayor parte todo de acá (Crescencio Anza, habitante de Toconce, com. pers., 2019). 
[...] podemos decir acá la gente vivió, construyó bajo una mira natural sin ninguna decir arquitectura por el hombre, sino como ellos podian vivir mejor haciendo su hogar (Honorio Ayavire, habitante de Ayquina, com. pers., 2019).

2. Vivienda "tradicional modificada". Llamada por los habitantes "Post Autóctona", "Autóctona medio", "Casa de la vida moderna", "Semi Natural", "Casa remodelada".

Se define como una vivienda que mantiene el mismo modelo o estructura que la tradicional, pero uno o más elementos fueron reemplazados por otro de tipo industrial. Se observa el reemplazo total o parcial de la techumbre, por otra de una o dos aguas con elementos de madera de pino y metálicos; el uso de morteros de cemento; uso de carpintería de madera de pino o elementos metálicos; la modificación de la proporción de los vanos, y/o el uso de enchape de piedra local como revestimiento de fachada principal exterior.

Según esto, los entrevistados calificaron esta vivienda como posterior a la tradicional en la medida que ya no cumple con todas las características propias de la zona, al introducir un elemento externo.

No cumple los requisitos de autóctono, no sé, no me cuadra, no cumple los requisitos por el techo. Autóctona medio, para identificarlo (Ascencio Anza, habitante de Caspana, com. pers., 2019).

Esa es más moderna ya, esa ya no es natural, seminaturales, porque casi tiene el mismo modelo, pero ya no tiene paja [en el techo] (Crescencio Anza, habitante de Toconce, com. pers., 2019).

3. Vivienda "tradicional simulada". Llamada por los habitantes "Casa moderna con bloque", "Casa para mantener lo típico", "Casa de las nuevas generaciones", "Imitación", "Simulación de autóctona", "Apariencia de antigua", "Casa moderna con tono antiguo":

Esta tipología de vivienda presenta como característica principal la representación consuetudinaria de la morfología tradicional y de la relación lleno-vacío, empleando nuevas técnicas con materiales locales o el empleo absoluto de materiales no locales, tales como madera de pino, cemento y elementos metálicos, pero siempre imitando la imagen tradicional. Así, se mantienen las dimensiones y forma general de las tipologías anteriores, sin embargo, no conserva ninguna materialidad tradicional de la zona. Los entrevistados la reconocieron como una vivienda que fue construida de tal manera como un acuerdo comunitario, para mantener la fachada tradicional de las casas en los pueblos, aplicando sobre la materialidad introducida un enchapado de piedra o revoque de barro, o pintando o colocando paja sobre los techos. Sin embargo, no se ha cumplido con este acuerdo en todos los casos.

Es una casa diría yo, más moderna, porque lo único que le tiraron es paja sobre la calamina nomás, para que no se note la calamina, le quisieron dar el tono. Algunos le pintan la calamina para que no se note la calamina. Es como una casa moderna con tono antiguo (Mario Ayavire, habitante de Toconce, com. pers., 2019).

Esa es para mantener lo típico, aqui no tenia que quedar a la vista el bloque, tenia que quedar más menos asi enchapado, con piedra, entonces aqui no cumplió las 
reglas, se exigió ser típico pero no está típico, se ve el bloque, es una casa moderna con bloque (Adrián Berna, habitante de Ayquina, com. pers., 2019).

4. Vivienda "disonante”. Llamada por los habitantes "Casa nueva”, "Construcción de ciudad", "Casa de trabajador de Codelco", "Moderna", "Casa de la vida actual", "Casa de gente de ciudad".

Esta vivienda no presenta ninguna similitud con las tipologías anteriores, escapando en su forma y materialidad, con transformaciones como la adición de un segundo nivel, ventanales de proporciones distintas y generalmente más grandes que las tipologías anteriores, e incorporación de elementos como el fierro y el cemento, es decir, todos los materiales empleados son de origen industrial. Considerando aquellas con cambios estructurales, existen diversas soluciones, por lo que, además del frecuente empleo de bloques de cemento, no se reconocen patrones en común, siendo esta tipología disonante un grupo que engloba lo ajeno al lugar.

Los entrevistados la identifican como una construcción ajena a lo tradicional de los pueblos, y que se ha percibido como una introducción desde los espacios urbanos.

No, esta no tiene nada, nada, nada, es moderna, es lo último ya, esta ya pasó a ser una construcción de ciudad, no acá del pueblo típico (Adrián Berna, habitante de Ayquina, com. pers., 2019).

Claro, con segundo piso, nuevas generaciones de gente que ya vive en las ciudades y no tienen esta costumbre de usar piedra y techo de paja, ninguna cuestión, ya es gente que no ha vivido casi nunca aqui en Ayquina (Honorio Ayavire, habitante de Ayquina, com. pers., 2019).

A partir de la caracterización de las tipologías, se clasifican las viviendas de cada poblado, dentro de un sector acotado. A partir de esta clasificación se obtienen los datos de la cantidad de viviendas de cada tipología por poblado, además de la cantidad de viviendas por tipología, a modo general. Estos datos se muestran en la Tabla 3:

Tabla 3. Resultados segundo terreno, enero 2019.

\begin{tabular}{|c|c|c|c|c|c|}
\hline \multirow{2}{*}{ Poblado } & \multirow{2}{*}{$\begin{array}{c}\text { Total } \\
\text { de viviendas }\end{array}$} & Tradicional & $\begin{array}{c}\text { Tradicional } \\
\text { modificada }\end{array}$ & $\begin{array}{c}\text { Tradicional } \\
\text { simulada }\end{array}$ & Disonante \\
\cline { 3 - 6 } & 255 & 46 & 102 & 41 & 66 \\
\hline Ayquina & 169 & 16 & 77 & 44 & 32 \\
\hline Toconce & 153 & 38 & 34 & 48 & 33 \\
\hline Caspana & $\mathbf{5 7 7}$ & $\mathbf{1 0 0}$ & $\mathbf{2 1 3}$ & $\mathbf{1 3 3}$ & $\mathbf{1 3 1}$ \\
\hline \multirow{2}{*}{ Totales } & $\mathbf{1 0 0 \%}$ & $\mathbf{1 7 \%}$ & $\mathbf{3 7 \%}$ & $\mathbf{2 3 \%}$ & $\mathbf{2 3} \%$ \\
\cline { 2 - 6 } & & & & & \\
\hline
\end{tabular}

Fuente: Elaboración propia. 
Según los datos obtenidos en la tabla anterior, en los poblados de Ayquina y Toconce, la tipología predominante es la "Tradicional modificada" y en segundo lugar la "Disonante", mientras en el poblado de Caspana la tipología predominante es la "Tradicional simulada" seguida por la "Tradicional".

\section{La cultura constructiva de Ayquina, Caspana y Toconce en la actualidad}

Para el análisis de la cultura constructiva presente en los poblados, no se puede negar la relación existente entre esta y las tipologías arquitectónicas encontradas. Una cultura constructiva, en palabras de Guerrero (2007), comprende la "elección de materias primas, procesos de transformación, acarreo y almacenamiento, las dimensiones de los elementos constructivos, sus formas de disposición [y] obedecen a una lógica en la que se han logrado optimizar los recursos disponibles, estableciendo límites de acción precisos que son conocidos y heredados entre los miembros de la comunidad que comparte la sabiduría regional" (p. XX). En otras palabras: existe una relación estrecha entre las características del territorio con las materias primas que este ofrece y el cómo una comunidad adapta esas materias para construir su hábitat, generando con ello no solo su morada, sino que una serie de prácticas inmateriales asociadas al acto de construir que, en palabras de hoy, son consideradas un ejemplo de sustentabilidad; de ahí que estudios recientes relacionen la arquitectura vernácula o tradicional con la sustentabilidad (Correia, Dipasquale y Mecca, 2014).

En el caso de la cultura constructiva likan antai, como se ha visto, los cambios socioeconómicos y territoriales acaecidos en las últimas décadas han llevado, entre otras consecuencias, al uso de materiales industriales en la construcción, los que han tenido una repercusión directa tanto en las prácticas de construcción como en la fisonomía de la arquitectura misma. De hecho, como se mencionó anteriormente, la tipología arquitectónica más abundante hoy, dentro de los tres poblados, es la "tradicional modificada", y en ella se hace evidente la transformación de la cultura constructiva característica de la zona, al producirse un reemplazo por materiales industriales en la vivienda, que han modificado las prácticas constructivas comunitarias.

Así, por ejemplo, según los relatos de los entrevistados, en el caso de los techos de las viviendas, antiguamente se organizaban "techamientos" para construir una estructura de paja y barro. Este se realizaba con la ayuda comunitaria de los vecinos, lo cual culminaba con una comida y un baile de celebración. No obstante, con la introducción del zinc, esta práctica cesó, al ser este nuevo elemento constructivo trabajado de manera individual: "Ahi ya no se usa por ejemplo, decir vamos a hacer un techamiento, van todos los vecinos ayudando. Ahi ya no ya, yo prácticamente lo techo solo, con martillo y clavo" (Adrián Berna, habitante de Ayquina, com. pers., 2019).

Respecto al reemplazo de la piedra como material tradicional de los muros por el bloque de cemento, los habitantes relatan que ellos siguen prefiriendo las construcciones con piedra, al ser de "mejor calidad", tomando en consideración la durabilidad y temperatura que este material otorga. Los motivos de este cambio varían según las opiniones de cada persona; sin embargo, existen algunas conclusiones comunes que refieren principalmente a la practicidad del bloque frente a la piedra, asociada a la facilidad de obtención, la disminución del tiempo destinado a su instalación, así como el requerir menor esfuerzo físico y mano de obra para la construcción. Los entrevistados argumentan que la piedra se ha convertido en un elemento escaso o difícil de recolectar y sostienen que cada vez es necesario realizar un recorrido más largo hacia los alrededores 
del pueblo para conseguir este elemento, además de necesitar la ayuda y disponibilidad de una cierta cantidad de personas para su obtención. De este modo, aun cuando el trabajo con la piedra es una técnica que se ha conservado entre las comunidades como una sabiduría que se ha traspasado de generación en generación, y que en cada pueblo visitado fue posible conversar con un maestro conocedor directo del trabajo con este material tradicional, este conocimiento llevado a la práctica se ha visto como un proceso en vías de desaparecer.

Las tipologías de la vivienda, "tradicional modificada", "tradicional simulada" y "disonante" dan cuenta de un escenario de transformación de la cultura constructiva no solo en términos físicos, sino también en relación a las prácticas, que ya no incluyen las mingas o trabajos comunitarios que solían verse asociados a la construcción de la vivienda tradicional. Detrás de estas tres nuevas tipologías de viviendas, son reducidos los casos en los cuales se apela al parentesco o vecindad para llevar a cabo los procesos constructivos, siendo entonces una práctica realizada por cada uno de forma independiente, o bien, contratando a un maestro que se dedica específicamente a esta labor.

Las transformaciones que han ocurrido se deben a diversos factores, como ya hemos señalado. Entre ellos, la facilidad y rapidez de los materiales industrializados y la especialización del trabajo constructivo han provocado, a su vez, que los costos de la mano de obra para trabajos con material tradicional sean más elevados que aquellos que se realizan con material industrial.

Sin embargo, como se ha mencionado anteriormente, la arquitectura y la cultura constructiva ancestral no han desaparecido del todo, y en los tres poblados en análisis se observa un proceso de hibridación entre lo contemporáneo industrial y lo ancestral, donde aún subsisten ciertas formas y prácticas tradicionales.

Así, respecto a la construcción de las techumbres, es en el recubrimiento con paja brava donde se registra el mayor cambio, reemplazando esta por las planchas de zinc, ya que la paja sufre más dańos con el transcurso del tiempo, y a la vez, porque es el material más escaso debido a la falta de lluvias y, por lo tanto, se privilegia su uso como alimento para las llamas. Sin embargo, de manera acotada se sigue usando la paja brava, pero encima de la cubierta de zinc -para mantener la fisonomía tradicional y ayudar a la aislación del techo-, y en otros casos sobre una capa de fieltro asfáltico usado como aislante. En cuanto a las prácticas asociadas a la búsqueda del material, en Caspana aún se va en burro a los cerros, mientras que en Toconce esta labor se realiza en camionetas de acercamiento que consiguen sus habitantes, para luego hacer el último trayecto a pie.

En cuanto a la estructura de techumbre, se observa tanto la incorporación de elementos de madera industrial de pino radiata o insigne y metálicas, comprados en su mayoría en Calama, como la utilización de maderas nativas como el algarrobo.

Respecto a los muros, además del mencionado uso del bloque de cemento, han aparecido nuevos sistemas de construcción en piedra. En Caspana, por ejemplo, se registran viviendas con pequeños mampuestos labrados, de un tamaño similar al de un ladrillo de arcilla y otros un poco más grandes, con dimensiones como los bloques de cemento. También existe la construcción con bloques de cemento recubiertos con unas especies de placas de piedra simulando una mampostería. En los tres poblados, se puede observar también el uso de fachada de piedra y el resto de la construcción en bloque de cemento confinado. 
En cuanto a los vanos de puertas y ventanas, ese ha sido otro de los elementos que ha presentado modificaciones, pues en su mayoría ahora se utilizan las puertas estándares de $2 \mathrm{~m}$ de altura y ventanas de aluminio también de medidas estándar, lo cual ha cambiado no solo la fisonomía de la arquitectura, sino también su habitabilidad, pues ahora las viviendas son más luminosas que las tradicionales, que se caracterizaban por ser oscuras.

Todos los cambios en los materiales, como se ha visto, llevan consigo una transformación en la arquitectura, en las prácticas constructivas y en la habitabilidad de las viviendas. De acuerdo a los testimonios recogidos, hay aspectos que se considera han mejorado con la introducción de materiales contemporáneos como la mayor entrada de luz a la vivienda gracias a los nuevos vanos. Lo anterior ha permitido que esta se ocupe durante más horas del día, mientras la vivienda tradicional, como se mencionó, hoy en muchos casos se usa como bodega. Por otra parte, el aspecto que se considera ha empeorado más es la temperatura percibida al interior de las viviendas, pues la morada tradicional de piedra con techumbre de paja brava y barro se consideraba más "calentita", mientras que las actuales se consideran heladas en invierno y calurosas en verano, debido a la transmitancia térmica propia de los materiales empleados y al hecho de que no se considera la incorporación de materiales aislantes y que las terminaciones no siempre son buenas, dejando espacios por donde entra el aire (puentes térmicos).

La introducción de nuevos materiales ha acentuado, además, las prácticas de movilidad, pues la mayor parte de ellos son adquiridos en Calama, y por lo tanto, el hecho de dejar de extraer materiales naturales del entorno inmediato conlleva en forma paulatina una pérdida del conocimiento acerca del territorio.

\section{Conclusiones}

La vivienda no es solo el lugar físico donde resguardarse de las inclemencias del medio ambiente, sino también el lugar de los afectos, donde se comparten las penas y las alegrías y donde "fijamos nuestra identidad, aprendemos a ver el mundo, a sentir, querer y actuar como atacameños; escuchamos a nuestros mayores y vemos crecer a nuestros hijos y nietos" (Calpanchay, 2011, p. 19). Entonces, esa casa ancestral, de fin de semana o de uso ocasional, sigue siendo el lugar de los afectos familiares, de arraigo con la cultura y el territorio andino, el espacio donde se genera y regenera la identidad. Por ello es que, a pesar de que gran parte de la comunidad likan antai vive actualmente en las ciudades, los poblados en torno al río Loa y al salar de Atacama no están abandonados y sus viviendas, nuevas o ancestrales, permanecen.

Como se vio en el artículo, la vivienda tradicional, "Natural" o "Antigua", como la llaman sus habitantes, a pesar de su brusca disminución representa aún alrededor de un 17\% del total de las viviendas de los poblados. Destinadas a bodegas o como lugares de conmemoración, son testimonio de los modos ancestrales de construir íntimamente relacionados con el conocimiento profundo de los recursos del territorio, y donde el uso de la piedra en sus diferentes expresiones aparece como un rasgo distintivo del construir likan antai, dando forma a los asentamientos y a una cultura constructiva que aún subsiste y que además ha dado lugar a paisajes únicos. En ese sentido, la vivienda tradicional likan antai es un patrimonio arquitectónico que posee múltiples atributos, entre ellos otorgar una identidad construida a un territorio, ser ejemplo de un habitar sustentable, al estar construida con materiales del lugar, poseer óptimas condiciones de habitabilidad y ser la manifestación física de formas colectivas del construir, cumpliendo con todos los principios establecidos en la Carta del Patrimonio Vernáculo construido (Consejo Internacional de Monumentos y Sitios, 1999). 
Sin embargo, como se describió, debido a múltiples factores socioeconómicos, globalización y capitalismo, las declaratorias que protegen especies de flora nativa, además de grandes sequías producto del cambio climático, las formas de habitar y construir han cambiado y las actuales prácticas hacen uso del esfuerzo individual, transformando las dinámicas de relación al interior de las mismas comunidades y entre estas y su territorio, pues ya no extraen de él los materiales de construcción.

Sin embargo, a pesar de las transformaciones físicas y de las prácticas, el arraigo identitario con la vivienda tradicional queda de manifiesto en el hecho de que el $60 \%$ de las viviendas actuales pertenecen a las categorías de vivienda "tradicional modificada" y "tradicional simulada”, lo que puede entenderse como un continuo de lo tradicional que se materializa en una arquitectura híbrida, como la define Pérez (2019, p. 3). Esto significa que, aun con el acceso a los materiales industrializados y a las formas modernas de construir, existe una representación y ciertos elementos de la vivienda tradicional "natural" que son constantes y que se busca -con ańoranza- imitar, aunque sea solo de manera escenográfica. Lo anterior da cuenta de una valoración de la comunidad likan antai hacia sus formas de construir ancestrales, las cuales logran reinterpretar a partir de prácticas y técnicas que se adaptan a su actual contexto. Si bien esto no siempre es explícito, en los testimonios recogidos también se aprecia la valoración de aspectos inmateriales y vivenciales como el mencionado confort térmico de las casas construidas con piedra, lo que sin duda nos sitúa frente a un proceso de patrimonialización latente que urge poner en evidencia.

El momento que cruza actualmente la vivienda likan antai, hace no solo necesario su registro, sino su protección como parte del patrimonio cultural inmaterial y material inmueble chileno, antes de que desaparezca completamente. La presente investigación pretendió contribuir a ese registro y a la valorización de las formas tradicionales de habitar y construir, a la vez que advertir acerca de lo que sucede hoy en los asentamientos likan antai, con el propósito de generar conocimiento que pueda ser útil a las mismas comunidades, a quienes toman decisiones, así como a los instrumentos de planificación territorial y desarrollo comunal.

\section{Agradecimientos}

Nuestros sinceros agradecimientos a las comunidades likan antai del sector del Alto Loa y el salar de Atacama que decidieron participar en este proyecto. A los dirigentes que nos brindaron una bienvenida y, en especial, a aquellas personas que dedicaron parte de sus días para conversar con nosotros. Un especial agradecimiento a Ricardo Cruz y su equipo de trabajo de la comunidad de Cupo, que mantienen vivas las tradiciones constructivas a través de la restauración de sitios comunitarios, quienes compartieron con nosotros parte de este saber.

A la Dirección de Obras Municipales de San Pedro de Atacama por su tiempo y colaboración.

A la Vicerrectoría de Investigación y Desarrollo (VID) de la Universidad de Chile por haber financiado el proyecto de investigación ENL 14/18 "Construir y habitar likan antai" que dio origen a este artículo. 


\section{Referencias citadas}

Arévalo, M. (2004). La tradición, el patrimonio y la identidad. Revista de estudios extremeños, 60(3), 925956.

Benavides, A. (1988 [1941]). La arquitectura en el virreinato del Perú y en la capitania general de Chile. Santiago: Editorial Andrés Bello.

Benavides, J. y Gutiérrez, R. (2006). La arquitectura en los andes del Capricornio. En Las rutas del Capricornio Andino (pp. 105- 118). Santiago: Consejo de Monumentos Nacionales.

Benavides, J., Márquez de la Plata, R. y Rodríguez, L. (1977). Arquitectura del Altiplano. Caseríos y villorrios ariqueños. Santiago: Editorial Universitaria.

Briones, C. (1994). Con la tradición de todas las generaciones pasadas gravitando sobre la mente de los vivos: Usos del pasado e invención de la tradición. Runa, XXI, 99-129, Sección Etnología y Etnografia, I.C.A. - CONICET.

Calpanchay, R. (2011). Construcción Andina: complementación entre Ciencia y Saberes Ancestrales. En Tomasi J. y Rivet, C. (Eds.). Puna y Arquitectura. Las formas locales de la construcción (pp. 19-22). Buenos Aires: Cedodal.

Chandía, R. (2013). Estrategias de gestión sostenible del territorio: cultura de riego alto-andino del desierto de atacama. Revista $A U S, 13,5-10$.

Consejo de Monumentos Nacionales (CMN) (s.a.). Lista Tentativa. Obtenido de: https://www.monumentos.gob.cl/patrimonio-mundial/lista-tentativa

Correia, M., Dipasquale, L. y Mecca, S. (2014). VERSUS: Heritage for Tomorrow: Vernacular knowledge for sustainable architecture. Florencia: Firenze University Press.

Egumfedt-Jorgense, Uslar, Tiska y Samper (1983). Asentamientos urbanos en territorios fronterizos, etapa de estudio zona Norte regiones I y II. Santiago: Pontificia Universidad Católica de Chile.

Escobar, I. (2017). Lecturas contextuales sobre los modos de asentamiento en el altiplano atacameño. Caso de estudio: poblado de Caspana, Chile. Revista de Arquitectura, 22(32), 51-58.

Fullerton, D. y Medina, P. (2017). Saberes Arquitectónicos, las formas vernáculas del Altiplano. Santiago: RIL editores.

González, H., Gundermann, H. e Hidalgo, J. (2014). Comunidad indígena y construcción histórica del espacio entre los Aymara del norte de Chile. Chungara. Revista de Antropología Chilena, 46(2), 233-246.

Gross, P. (2006). Gestión para la conservación y recuperación patrimonial. En Reconstruyendo con la madre tierra (pp. 32-35). Santiago: Cuadernos del Consejo de Monumentos Nacionales, 108.

Gross, P. (2015). Arquitectura en Chile. Desde la prehispanidad al centenario. Santiago: Editorial Sa Cabana.

Guerrero, L. (2007). Arquitectura en tierra. Hacia la recuperación de una cultura constructiva. Apuntes, 20(2), 182-201.

Hurtado, M. (2012). Aportaciones andinas a la construcción de una identidad local. Revista 180, 30, 36-39. 
Jorquera, N. (2010). Las iglesias del altiplano: un modelo de fusión entre el mundo hispánico y andino. En Fernández, M. y Correia, M. (Eds.). Terra em Seminário 2010 (pp. 125-129). Lisboa: Argumentum.

Jorquera, N. (2013). El patrimonio vernacular, fuente de saberes tecnológicos y de sostenibilidad. En Cordero, E. (Ed.). Taller [Sur] 2012 (pp. 175-185). Universidad Austral de Chile, Valdivia, Chile.

Jorquera, N. (2014). Aprendiendo del patrimonio vernáculo: tradición e innovación en el uso de la quincha en la arquitectura chilena. Revista de Arquitectura, 28/29, 4-11.

Kapstein, G. (2015 [1988]). Espacios Intermedios: respuesta arquitectónica al medio ambiente. Santiago: Ediciones ARQ.

Madrazo, M. (2005). Algunas consideraciones en torno al significado de la tradición. Contribuciones desde Coatepec (pp. 115-132). Universidad Autónoma del Estado de México, Toluca, México.

Moneo, R. (1978). On Typology. Oppositions, 13, 188-211.

Montandón, R. (1950). Iglesias y capillas coloniales en el Desierto de Atacama. Santiago, Chile: Consejo de Monumentos Nacionales - Imprenta Universitaria.

Oliver, P. (1997). Encyclopedia of Vernacular Architecture of the World. Cambridge: University Press.

Pérez, J. (2019). El palomar de Manolo. Estudio de caso de arquitectura vernácula desde el paradigma cultural. Memoria y Civilización, 22, 1-30.

Rapoport, A. (1969). House form and culture. Englewood Cliffs, NJ: Prentice Hall.

Riquelme, A. (2006). Daño sísmico en el patrimonio arquitectónico de la región de Tarapacá. En Reconstruyendo con la madre tierra (pp. 32-35). Santiago: Cuadernos del Consejo de Monumentos Nacionales 108.

Rivera, F. (1997). Procesos de articulaciones socio-identitarias y reformulaciones étnicas en Atacama. Estudios Atacameños, 13, 61-73.

Rudofsky, B. (1964). Architecture Without Architects: A Short Introduction to Non-pedigreed Architecture. New Mexico, NM: UNM Press.

Serrano, M. (2017). Levantamiento arquitectónico y cultura constructiva de la vivienda vernácula en San Pedro de Atacama. Antofagasta, Chile: Fondo Nacional de Desarrollo Cultural y las Artes.

Šolc, V. (2011 [1975]). Casa Aymara en Enquelga. Chungara. Revista de Antropología Chilena, 43(1), 89-111.

SONAMI. Mapa Minero de Chile. https://www.sonami.cl/mapaminero/

Tillería, J. (2010). La arquitectura sin arquitectos, algunas reflexiones sobre arquitectura vernácula. Revista AUS, 8, 12-15.

Tomasi, J. (2009). El lugar de la construcción: prácticas y saberes en la puna argentina. Buenos Aires: CUADERNOS FHyCS-UNJu, 36, 141-157.

Tomasi, J. y Rivet, C. (2011). Puna y Arquitectura. Las formas locales de la construcción. Buenos Aires: Cedodal. 